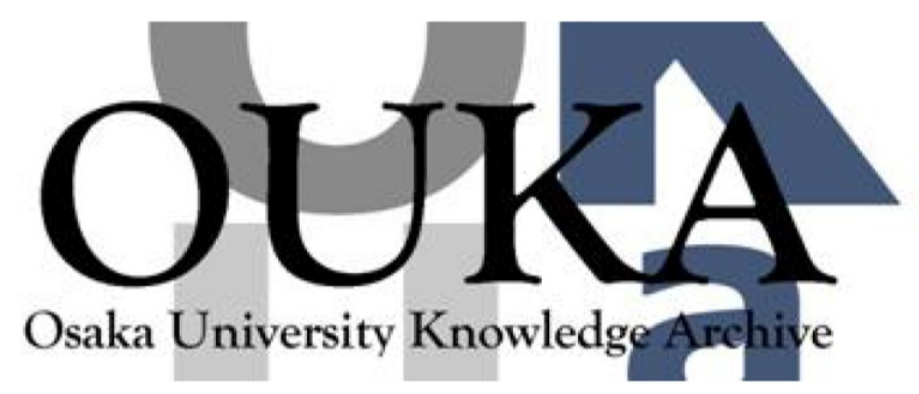

\begin{tabular}{|c|l|}
\hline Title & $\begin{array}{l}\text { Characterization of mouse lre1 } \alpha \text { : cloning, } \\
\text { mRNA localization in the brain and functional } \\
\text { analysis in a neural cell line }\end{array}$ \\
\hline Author(s) & Miyoshi, Ko \\
\hline Citation & \\
\hline Issue Date & \\
\hline oaire:version & VoR \\
\hline URL & https://hdl. handle.net/11094/43697 \\
\hline rights & \\
\hline Note & \\
\hline
\end{tabular}

Osaka University Knowledge Archive : OUKA

https://ir. Library. osaka-u. ac. jp/

Osaka University 


\title{
Characterization of mouse Ire1 $\alpha$ : cloning, mRNA localization in the brain and functional analysis in a neural cell line
}

\author{
Ko Miyoshi $^{\text {a,c,* }}$, Taiichi Katayamaa,b,c Kazunori Imaizumi ${ }^{\text {a,b,c }}$, Manabu Taniguchi ${ }^{\text {a,c }}$, \\ Yasutake Mori $^{\mathrm{a}, \mathrm{c}}$, Junichi Hitomi ${ }^{\mathrm{a}, \mathrm{c}}$, Daishi Yui ${ }^{\mathrm{a}, \mathrm{c}}$, Takayuki Manabe ${ }^{\mathrm{a}, \mathrm{c}}$, Fumi Gomi ${ }^{\mathrm{a}, \mathrm{c}}$, \\ Takunari Yoneda $^{\mathrm{a}, \mathrm{c}}$, Masaya Tohyama ${ }^{\mathrm{a}, \mathrm{c}}$ \\ ${ }^{a}$ Department of Anatomy and Neuroscience, Graduate School of Medicine, Osaka University, 2-2 Yamadaoka, Suita, Osaka 565-0871, Japan \\ ${ }^{\mathrm{b}}$ Tanabe Seiyaku Company Limited, Yodogawaku, Osaka 532-0031, Japan \\ ${ }^{\mathrm{c} C R E S T}$ of Japan Science and Technology Corporation (JST), Kawaguchi, Saitama 332-0012, Japan
}

Accepted 26 September 2000

\begin{abstract}
In yeast, an endoplasmic reticulum (ER)-associated protein, Ire1p, is believed to initiate the unfolded protein response (UPR), that is responsible for protein folding in the ER under stressed conditions. Two mammalian homologs of Ire $1 \mathrm{p}$ have been identified, Ire $1 \alpha$ and Ire $1 \beta$. We have previously reported that familial Alzheimer's disease linked presenilin-1 variants downregulate the signaling pathway of the UPR by affecting the phosphorylation of Ire1 $\alpha$. In the present study, we cloned the mouse homolog of Ire $1 \alpha$ for generating genetically modified mice. Ire1 $\alpha$ was ubiquitously expressed in all mouse tissues examined, and was expressed preferentially in neuronal cells in mouse brain. This led us to investigate the effects of the downregulation of the UPR on the survival of neuronal cells under conditions of ER stress. Morphological and biochemical studies using a dominant-negative form of mouse Ire1 $\alpha$ have revealed that cell death caused by ER stress can be attributed to apoptosis, and that the downregulation of the UPR enhances the apoptotic process in the mouse neuroblastoma cell line, Neuro2a. Our results indicate that genetically modified mice such as transgenic mice with a dominant-negative form of Ire $1 \alpha$ might provide further understanding of the pathogenic mechanisms of Alzheimer's disease and other neurodegenerative disorders. (c) 2000 Elsevier Science B.V. All rights reserved.
\end{abstract}

Theme: Cellular and molecular biology

Topic: Gene structure and function: general

Keywords: Ire1 $\alpha$; ER stress; UPR; Alzheimer's disease; Neuro2a

\section{Introduction}

Various cell stresses such as perturbation of calcium homeostasis, deprivation of trophic factors and oxidative insults cause accumulation of unfolded proteins in the endoplasmic reticulum (ER). Cells respond to these ER stresses by increasing transcription of genes encoding ERresident chaperones such as GRP78/BiP, GRP94, calreticulin and protein disulfide isomerase (PDI), which facilitate protein folding in the ER. This induction system is termed the unfolded protein response (UPR; reviewed in

\footnotetext{
*Corresponding author. Tel.: +81-6-6879-3221; fax: +81-6-68793229.

E-mail address: miyoshi@anat2.med.osaka-u.ac.jp (K. Miyoshi).
}

Ref. [14]). In yeast, the UPR signaling is initiated by Ire1p/Ern1p, an ER-associated type I transmembrane protein that contains both serine/threonine kinase and ribonuclease domains in its cytosolic portion $[1,8,13,18]$. The ER-lumenal portion of Ire1p is thought to sense the perturbed environment in the ER, followed by oligomerization and trans-phosphorylation of the kinase domain $[12,18]$, and downstream signaling through the activation of a sequence-specific ribonuclease activity [13]. Two mammalian homologs of yeast Ire1p have been identified, Ire1 $\alpha$ [16] and Ire1 $\beta$ [17]. The expression of Ire $1 \beta$ is limited to the lung and the intestine, where its expression level is very low (our unpublished data). Recently we showed that familial Alzheimer's disease (FAD) linked presenilin-1 variants downregulate the signaling pathway 
of the UPR by affecting the phosphorylation of Ire1 $\alpha$ [4], suggesting that Ire $1 \alpha$ might be one of the components that participate in pathogenic mechanisms in brains of FAD patients.

In mammalians, little has been understood about in vivo expression of Ire $1 \alpha$ and the mechanism by which Ire $1 \alpha$ senses ER stress and activates the downstream pathway of the UPR. Here, we cloned the mouse homolog of Ire $1 \alpha$ for generating genetically modified mice, and investigated the expression of Ire $1 \alpha$ mRNA in mouse tissues. In situ hybridization analysis has revealed that in mouse brain Ire $1 \alpha$ mRNA is expressed preferentially in neuronal cells, which led us to investigate the effects of the downregulation of the UPR in a mouse neuroblastoma cell line, Neuro2a, using a dominant-negative form of mouse Ire $1 \alpha$. Morphological and biochemical studies have shown that cell death caused by ER stress can be attributed to apoptosis, and that the downregulation of the UPR enhances the apoptotic process.

\section{Materials and methods}

\subsection{Animals}

Adult ddY mice ( 8 weeks old) weighing $\sim 25 \mathrm{~g}$ were anesthetized with ether inhalation and decapitated. Several tissues were then promptly removed. Brains were also removed from embryonic 14- and 18-day, and postnatal 1-, 7- and 14-day ddY mice.

\section{2. $c D N A$ cloning}

Approximately one million colonies from a unidirectional oligo (dT) primed mouse brain cDNA library (C57 Black/6, female, 19 weeks; Stratagene) were screened by hybridizing to the insert of a mouse expressed sequence tag (EST) clone J0729C04 (Genbank accession \#AU016754). The library screening was performed by standard methods.

\section{3. $R T-P C R$}

Total RNA was isolated from mouse tissues by extraction with Rneasy Mini Kit (QIAGEN) according to the manufacturer's instructions. Five micrograms of each total RNA were reverse-transcribed into first strand cDNA using Ready-To-Go You-Prime First-Strand Beads (Amersham Pharmacia) with the reaction volume of $33 \mu \mathrm{l}$ according to the manufacturer's instructions. One microlitre of the reaction mixture was then amplified by PCR using Taq DNA polymerase (TaKaRa) and primer pairs designed for the specific detection of mouse Ire $1 \alpha$ and $\beta$-Actin (as an internal control) cDNA target sequences. PCR was performed using the following conditions: after an initial denaturation of $2 \mathrm{~min}$ at $95^{\circ} \mathrm{C}$, the amplification profile consisted of $30 \mathrm{~s}$ at $95^{\circ} \mathrm{C}, 1 \mathrm{~min}$ annealing, $30 \mathrm{~s}$ at $72^{\circ} \mathrm{C}$ for 29 cycles (for the tissue distribution of Ire $1 \alpha$ ), 31 cycles (for the developmental changes of Ire $1 \alpha$ in brain) or 18 cycles (for $\beta$-Actin). The annealing temperatures were $68^{\circ} \mathrm{C}$ for Ire $1 \alpha$ and $60^{\circ} \mathrm{C}$ for $\beta$-Actin. The primers used in this experiment were $5^{\prime}$-CCCTGATAGGTTGAATCCTGGCTATGTG-3' (sense) and 5'-AATCTATGCGCTAATCTGCTGGCCTCTG-3' (antisense) for Ire $1 \alpha$ and $5^{\prime}$-AGCTGAGAGGGAAATCGTGC-3' (sense) and 5'-ACCAGACAGCACTGTGTTGG-3' (antisense) for $\beta$-Actin. The PCR products were separated by $4 \%$ acrylamide gel electrophoresis and visualized by staining with ethidium bromide.

\subsection{In situ hybridization}

Frozen sections (15 $\mu \mathrm{m}$ thick) of adult mouse brain ( 8 weeks old) were cut in various planes and thaw-mounted onto poly-L-lysine-coated slides. Digoxigenin-labeled cRNA probes (antisense and sense) were generated by in vitro transcription using a cDNA fragment (2980-3426 nt) of mouse Ire $1 \alpha$ as a template in the presence of digoxigenin-labeled dUTP (Boehringer Mannheim). Hybridization and posthybridization procedures were performed as described previously [3].

\subsection{Expression plasmids}

The coding region of mouse Ire $1 \alpha$ cDNA was cloned into pcDNA3.1(+) at KpnI and ApaI sites. A truncated form of mouse Ire $1 \alpha$ cDNA, $\Delta$ Ire $1 \alpha$, that lacked the sequence of kinase and ribonuclease domains, was generated and tagged with a Flag-epitope sequence at its Cterminal by PCR using wild-type cDNA as a template, and also cloned into pcDNA3.1(+) at the same sites.

\subsection{Cell culture and assessment of apoptosis by Hoechst 33258 staining}

Neuro2a cells, a mouse neuroblastoma cell line, were stably transfected with mock (empty plasmid), wild-type mouse Ire $1 \alpha$ cDNA or a truncated form, $\Delta$ Ire $1 \alpha$. Two lines were selected from the stable lines transfected with mock (\#3, \#8), wild-type (\#3, \#10) and $\Delta \operatorname{Ire} 1 \alpha(\# 2, \# 5)$, respectively. They were replated on $10-\mathrm{cm}$ dishes at a density of $2 \times 10^{3}$ cells $/ \mathrm{cm}^{2}$, maintained in $\alpha$-MEM (Life Technologies) containing $10 \%$ fetal calf serum at $37^{\circ} \mathrm{C}$ for $48 \mathrm{~h}$ and then treated with $2 \mu \mathrm{g} / \mathrm{ml}$ tunicamycin (Sigma) or $3 \mu \mathrm{M}$ A23187 (Sigma) in the same medium. At 10, 20, 30 or $40 \mathrm{~h}$ after treatment, cells were stained with $5 \mu \mathrm{g} / \mathrm{ml}$ Hoechst 33258 (Molecular Probes) in PBS for $15 \mathrm{~min}$. The average percentages of cells with chromatin condensation in randomly selected fields were scored as an indicator of apoptosis under UV illumination. 
A

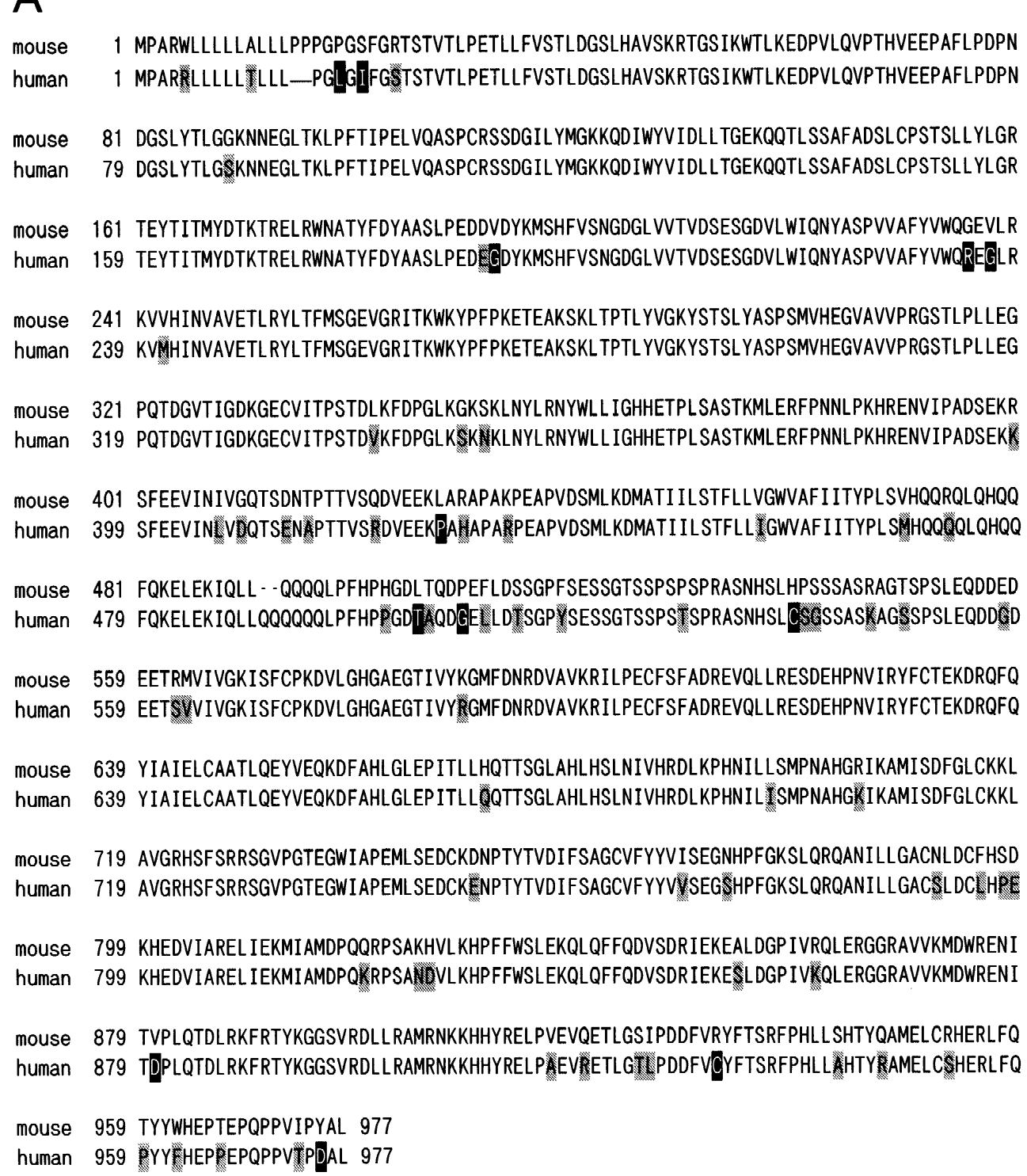

B

\section{ER-lumenal Cytosolic}

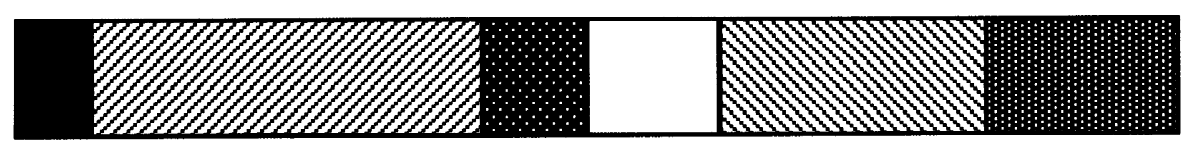

SP sensor domain TM linker Ser/Thr ribonuclease region kinase domain domain

Fig. 1. Amino acid sequence analysis and structure of mouse Ire1 $\alpha$. (A) Alignment of mouse and human Ire1 $\alpha$ amino acid sequences. Black boxes and shaded boxes represent nonconserved and conserved amino acids, respectively. All other amino acids are identical. Mouse and human sequences share a 92\% identity. GenBank accession number for the mouse cDNA sequence is AB031332. (B) Domain organization of mouse Ire1 $\alpha$. SP and TM refer to the potential signal peptide and the putative transmembrane domain, respectively. 


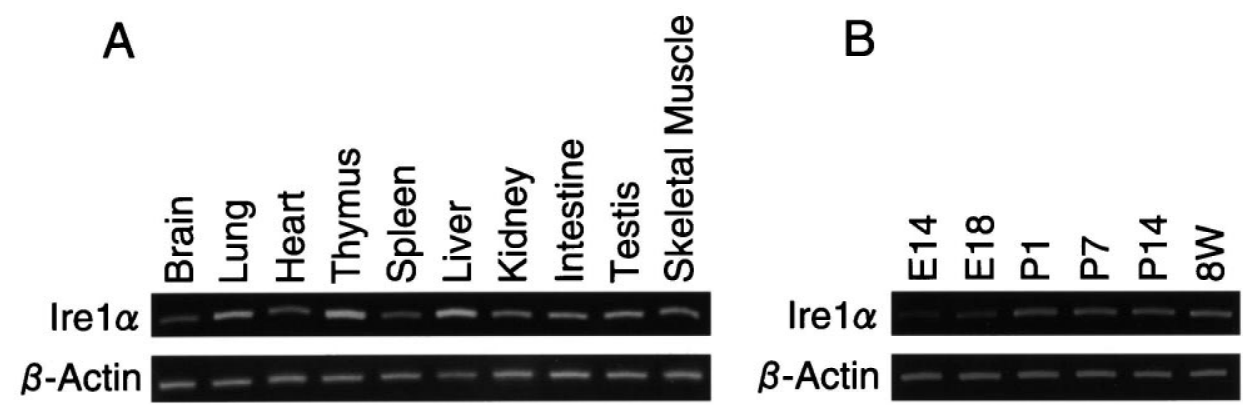

Fig. 2. The expression of mouse Ire1 $\alpha$ mRNA was investigated by RT-PCR. Total RNA was isolated from different tissues of adult mice (A) and brains of mice at several developmental stages (B), and reverse-transcribed into cDNA, that was then amplified by PCR using a primer pair designed for the specific detection of mouse Ire $1 \alpha . \beta$-Actin was also examined as an internal control. E14, E18, P1, P7, P14 and 8W refer to embryonic 14 and 18 days, and postnatal 1,7 and 14 days, and 8 weeks old, respectively.

\subsection{Electron microscopy}

Neuro2a cells expressing $\Delta \operatorname{Ire} 1 \alpha$ were treated with 2 $\mu \mathrm{g} / \mathrm{ml}$ tunicamycin for $40 \mathrm{~h}$. PBS containing $2 \%$ glutaraldehyde and $4 \%$ paraformaldehyde was then employed in fixing the cells at $4^{\circ} \mathrm{C}$ for $45 \mathrm{~min}$. They were post-fixed in $1 \% \mathrm{OsO}_{4}$ at $25^{\circ} \mathrm{C}$ for $30 \mathrm{~min}$, dehydrated in the graded ethanol solutions and embedded in Quetol 812 (NISSHIN EM Co.). Areas containing cells with apoptotic morphology were block-mounted and cut into $80-n m$ sections. The sections were stained with uranyl acetate $(10 \%$ in $50 \%$ ethanol) and lead citrate, and then examined with a Hitachi H-7100 electron microscope.

\subsection{Measurement of caspase-3-like activity}

Stable Neuro2a lines treated with $2 \mu \mathrm{g} / \mathrm{ml}$ tunicamycin for $40 \mathrm{~h}$ were washed with PBS, harvested and lysed by ICE buffer (50 mM Tris-HCl (pH 7.4), 1 mM EDTA and $10 \mathrm{mM}$ EGTA) containing $10 \mu \mathrm{M}$ digitonin. The lysates were then incubated at $37^{\circ} \mathrm{C}$ for $10 \mathrm{~min}$ and centrifuged at $15,000 \mathrm{rev} . / \mathrm{min}$ for $10 \mathrm{~min}$. Each sample (50 $\mu \mathrm{g}$ protein) was incubated with $50 \mu \mathrm{M}$ of Ac-DEVD-MCA (Peptide Institute, Inc.), the substrate for caspase-3, in ICE buffer with the reaction volume of $1 \mathrm{ml}$ at $37^{\circ} \mathrm{C}$ for $30 \mathrm{~min}$. Levels of released 7-amino-4-methylcoumarin (AMC) were measured using a spectrofluorometer with excitation at $380 \mathrm{~nm}$ and emission at $460 \mathrm{~nm}$.

\subsection{Western blot analysis}

The expression levels of wild-type Ire $1 \alpha$ and $\Delta \operatorname{Ire} 1 \alpha$ in stable Neuro2a lines were demonstrated by Western blot analysis. Cells were washed with PBS, harvested and lysed in NP-40 lysis buffer (1\% NP-40, $10 \mathrm{mM}$ Tris- $\mathrm{HCl}(\mathrm{pH}$ 7.8), $150 \mathrm{mM} \mathrm{NaCl}, 1 \mathrm{mM}$ EDTA, $1 \mathrm{mM}$ phenylmethylsulphonyl fluoride (PMSF) and $10 \mu \mathrm{g} / \mathrm{ml}$ aprotinin). The lysates were then incubated on ice for $50 \mathrm{~min}$, centrifuged at $15,000 \times g$ for $20 \mathrm{~min}$ and boiled for $5 \mathrm{~min}$ with SDS sample buffer. Equal amounts of protein $(30 \mu \mathrm{g})$ were subjected to $10 \%$ SDS-PAGE, transferred to PVDF mem- brane and blotted with rabbit polyclonal anti-Ire $1 \alpha$ antibody, which was made by injecting rabbits with the cytosolic portion of Ire $1 \alpha-G S T$ fusion protein. The membrane was then incubated with alkaline phosphatase-conjugated sheep anti-rabbit IgG antibody (Boehringer Mannheim). For Western blot analysis of caspase-3, Neuro2a lines which were treated with $2 \mu \mathrm{g} / \mathrm{ml}$ tunicamycin for 40 $h$ were lysed in NP-40 lysis buffer. The samples were prepared by the same procedures as the analysis of Ire $1 \alpha$. Equal amounts of protein $(30 \mu \mathrm{g})$ were subjected to $12 \%$ SDS-PAGE, and Western blot analysis was performed using rabbit polyclonal anti-caspase-3 antibody (Santa Cruz), which recognizes pro-caspase- 3 and active subunits, as the primary antibody, and anti-rabbit $\operatorname{IgG}$ antibody as the secondary antibody. For Western blot analysis of cytochrome $c$, Neuro2a cells expressing $\Delta \operatorname{Ire} 1 \alpha$ which were treated with $2 \mu \mathrm{g} / \mathrm{ml}$ tunicamycin for 12,24 or $40 \mathrm{~h}$ were harvested by centrifugation, and the cell pellets then washed with PBS and resuspended with buffer A $(50 \mathrm{mM}$ Tris-HCl pH 8.0, $1 \mathrm{mM}$ EDTA, $0.32 \mathrm{M}$ sucrose and 0.1 $\mathrm{mM}$ PMSF). The cells were homogenized with 10 strokes of a Teflon homogenizer, and the homogenates then separated as cytosol and membrane fractions by ultracentrifugation at $105,000 \times \mathrm{g}$ for $60 \mathrm{~min}$. Equal amounts of protein $(6 \mu \mathrm{g})$ from the cytosol fraction were subjected to $12 \%$ SDS-PAGE, and Western blot analysis was performed using mouse monoclonal anti-cytochrome $c$ antibody (PharMingen) as the primary antibody, and goat anti-mouse IgG antibody (Sigma) as the secondary antibody.

\section{Results}

\subsection{Isolation of complementary DNA encoding mouse Ire $1 \alpha$}

A mouse expressed sequence tag (EST) clone J0729C04 was found to have significant sequence homology to a portion of human Ire $1 \alpha$ cDNA. The clone was used as the probe to screen a mouse brain cDNA library (C57 Black/ 
6, female, 19 weeks; Stratagene) and an $\sim 4.0-\mathrm{kb}$ cDNA that contains an ORF encoding 977 amino acid residues was obtained from several overlapping clones and deposited in the DDBJ/EMBL/GenBank (accession \#AB031332). The amino acid sequence had a 92\% identity to that of human Ire1 $\alpha$, indicating that the cDNA encodes a mouse homolog of Ire $1 \alpha$ (Fig. 1A). Domain organization of mouse Ire $1 \alpha$ is shown in Fig. 1B. The encoded protein has an N-terminal hydrophobic stretch of 20 residues, thought to function as a signal peptide, followed by the sensor domain. A 21-residue hydrophobic stretch, predicted to serve as a transmembrane domain, locates approximately in the middle of the molecule. The C-terminal half of the protein contains a linker region, the serine/threonine kinase domain and the ribonuclease domain. The amino acid sequence identity between mouse Ire $1 \alpha$ and $\beta$ was $49 \%$.

\subsection{The expression of mouse Ire $1 \alpha$ mRNA}

The distribution of Ire $1 \alpha$ mRNA was analyzed by RTPCR on different tissues from adult mouse (Fig. 2A). Ire $1 \alpha$ was ubiquitously expressed in all tissues examined; it was expressed at relatively high levels in thymus, liver and lung. To examine the changes of Ire $1 \alpha$ mRNA expression during brain development, RT-PCR was performed on the brains of embryonic 14 (E14) and 18 (E18) day, and postnatal 1 (P1), 7 (P7) and 14 (P14) day, and 8-week-old (8W) mice (Fig. 2B). A gradual increase in the expression of Ire $1 \alpha$ mRNA along brain development was observed before P1, while the expression level was almost equivalent through the postnatal and adult stages.

\subsection{In situ localization of Ire 1 mRNA in mouse brain}

In situ hybridization using cRNA probes was carried out to analyze the distribution of cells expressing Ire $1 \alpha$ mRNA in mouse brain (Fig. 3). Fresh-frozen sections of brains from adult mice ( 8 weeks old) were hybridized with digoxigenin-labeled cRNA antisense and sense probes. Ire $1 \alpha$ mRNA was expressed in cortical neurons (Fig. 3A and B), hippocampal neurons (Fig. 3A and C) and olfactor neurons (Fig. 3D and E). Signal intensity on cortical neurons was equivalent in all sections examined. In hippocampus, Ire1 $\alpha$ mRNA was expressed in pyramidal cells of CA1-3 and granule cells of dentate gyrus, with the expression level in these hippocampal neurons being equivalent. In olfactory bulb, signals with relatively weak intensity were detected in mitral and granule cells. Very weak signals for Ire1 $\alpha$ mRNA were diffusely detected in other neuronal cells in mouse brain containing Purkinje cells and brainstem neurons. Signals were undetectable in oligodendrocytes and astrocytes.

\subsection{The involvement of apoptosis in cell death induced by the downregulation of the UPR}

The preferential expression of Ire $1 \alpha$ in neuronal cells in mouse brain led us to perform function analysis of Ire $1 \alpha$ in a mouse neural cell line. In yeast, overexpression of a truncated form of Ire1p that lacks an effector domain can downregulate the activation of the pathway that leads to the induction of $K A R 2 / G R P 78$ [8,12]. In mammalian cells, derivatives of Ire $1 \alpha$ and $\beta$ that lack the cytosolic portion have been shown to demonstrate similar dominantnegative effects on the UPR $[8,10]$. In the present study, a truncated form of mouse Ire $1 \alpha, \Delta \operatorname{Ire} 1 \alpha$, that lacked kinase and ribonuclease domains (Fig. 4A) was used to interfere with the activity of the endogenous inducers of the UPR in Neuro2a cells, a mouse neuroblastoma cell line. We confirmed that the levels of GRP78 mRNA induction in Neuro2a cells expressing $\Delta$ Ire1 $\alpha$ were lower than those in cells expressing wild-type Ire $1 \alpha$ or mock (empty plasmid) after treatment with tunicamycin or A23187 (data not shown), indicating dominant-negative effects of $\Delta \operatorname{Ire} 1 \alpha$ on the UPR; tunicamycin and A23187 are known to provoke ER stress by inhibition of protein glycosylation or perturbation of calcium homeostasis, respectively. To analyze the effects of the downregulation of the UPR, we examined the time-course of cell viability under conditions of ER stress in Neuro2a cells by investigating nuclear morphology with Hoechst 33258 staining (Fig. 4C and D). Neuro2a cells expressing a truncated form of Ire $1 \alpha, \Delta \operatorname{Ire} 1 \alpha$, displayed chromatin condensation, that is the morphological feature of apoptosis, at a significantly higher rate than cells expressing wild-type or mock at $20 \mathrm{~h}$ or later after treatment with $2 \mu \mathrm{g} / \mathrm{ml}$ tunicamycin (Fig. 4C). A significantly increased rate of apoptotic morphology of cells expressing $\Delta$ Ire $1 \alpha$ was also observed after treatment with $3 \mu \mathrm{M}$ A23187 (Fig. 4D), suggesting that the downregulation of the UPR enhances the apoptotic process under conditions of ER stress in Neuro2a cells. The morphological change described above that was revealed by Hoechst 33258 staining is shown in Fig. 5A. Neuro2a cells expressing $\Delta \operatorname{Ire} 1 \alpha$ treated with tunicamycin were also examined under electron microscopy (Fig. 5B). They exhibited changes consistent with apoptosis, such as loss of cytoplasm and nuclear fragmentation. Enlarged ER lumens were also observed, indicating that the cells were under conditions of ER stress.

In mammalian cells, a family of cysteine proteases termed caspases are known to be activated during the apoptotic process (reviewed in Ref. [15]). To examine the biochemical features of cell death induced by the downregulation of the UPR, we measured caspase-3-like protease activity in ER-stress exposed Neuro2a cells (Fig. 6A). At $40 \mathrm{~h}$ after treatment with tunicamycin, caspase-3like activity in Neuro2a cells expressing $\Delta \operatorname{Ire} 1 \alpha$ was significantly higher than that in cells expressing wild-type 

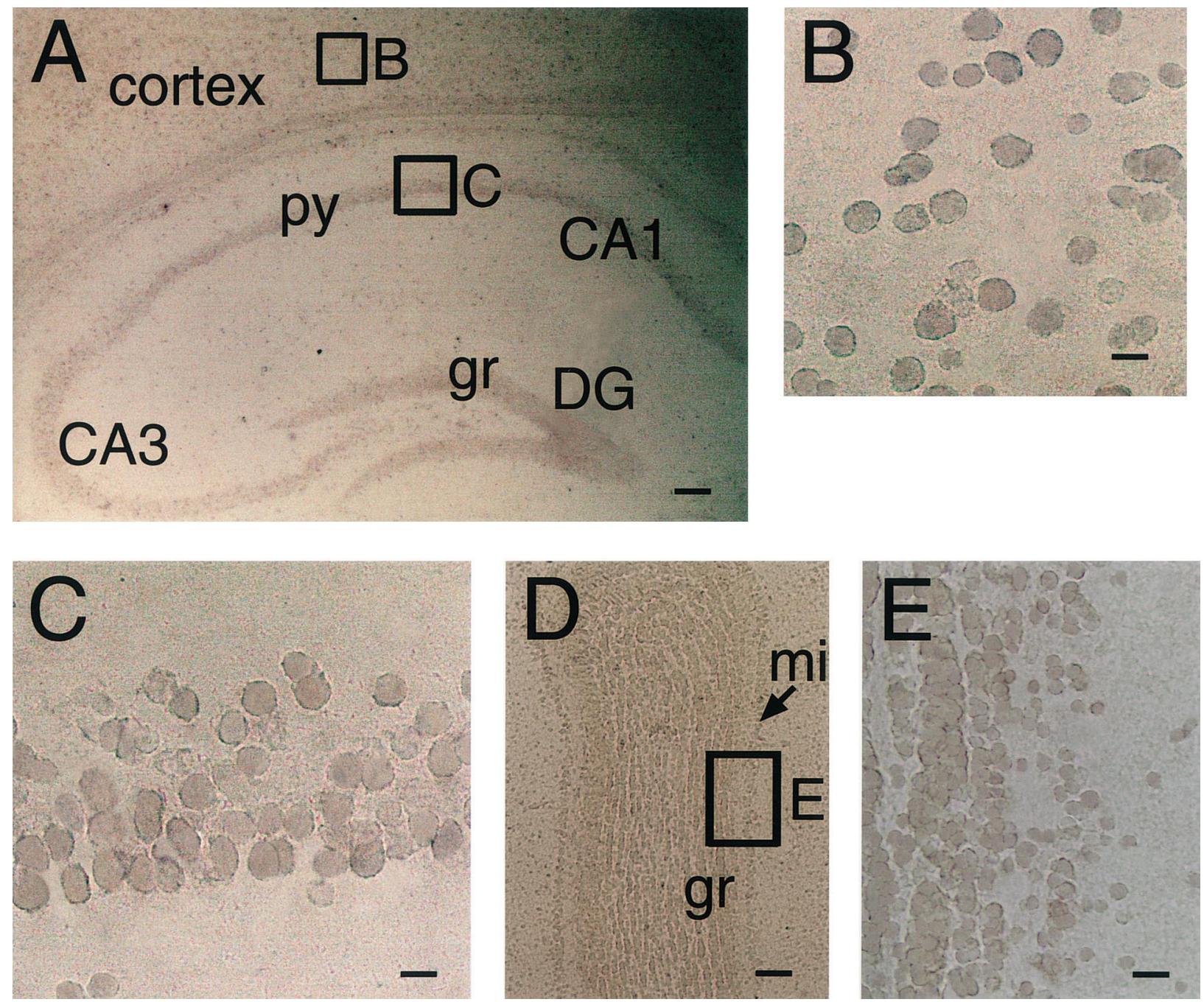

Fig. 3. In situ hybridization analysis of Ire $1 \alpha$ mRNA in mouse brain. Signals were detected in neuronal cells of the cortex and hippocampus (A), and in the olfactory bulb (D). High magnification views are shown for cortical neurons (B), hippocampal CA1 pyramidal cells (C), and olfactor mitral and granule cells (E). DG, dentate gyrus; py, pyramidal cell layer; gr, granule cell layer; mi, mitral cell layer. Scale bars: $100 \mu \mathrm{m}$ for (A), (D); $10 \mu \mathrm{m}$ for (B), (C); 20 $\mu \mathrm{m}$ for (E).

or mock. Caspase-3 is synthesized as a $32-\mathrm{kDa}$ precursor (pro-caspase-3), that is activated proteolytically into 20,19 or $17 \mathrm{kDa}$ subunits when cells are undergoing the apoptotic process [2]. To confirm the involvement of caspase3 in cell death induced by the downregulation of the UPR, we examined the cleavage of caspase- 3 in ER-stress exposed Neuro2a cells by Western blot analysis using an anti-caspase-3 antibody that can detect the proform and active subunits (Fig. 6B). The processing of caspase- 3 was observed in Neuro2a cells treated with tunicamycin for 40 h. Active fragments of caspase-3 were more abundant in cells expressing $\Delta \operatorname{Ire} 1 \alpha$ than in cells expressing wild-type or mock, suggesting that caspases contribute to cell death enhanced by the downregulation of the UPR in Neuro2a cells.

When cells are exposed to stimuli that trigger apoptosis, cytochrome $c$ is rapidly released from mitochondria into the cytosol where it activates caspases [5-7,19]. We therefore examined cytosolic cytochrome $c$ in ER-stress exposed Neuro2a cells expressing $\Delta$ Ire $1 \alpha$ by Western blot analysis (Fig. 6C). Cytochrome $c$ was detected in the cytosol fraction at $12 \mathrm{~h}$ after treatment with tunicamycin, and became more abundant at 24 and $40 \mathrm{~h}$. This cytochrome $c$ release into the cytosol from mitochondria preceded the morphological changes of cells demonstrated in Fig. 4, suggesting that cytochrome $c$ might play a key role in the course of cell death enhanced by the downregulation of the UPR in Neuro2a cells.

These morphological and biochemical findings suggest that cell death caused by ER stress in Neuro2a cells can be attributed to apoptosis and that the downregulation of the UPR enhances the apoptotic process. 
A
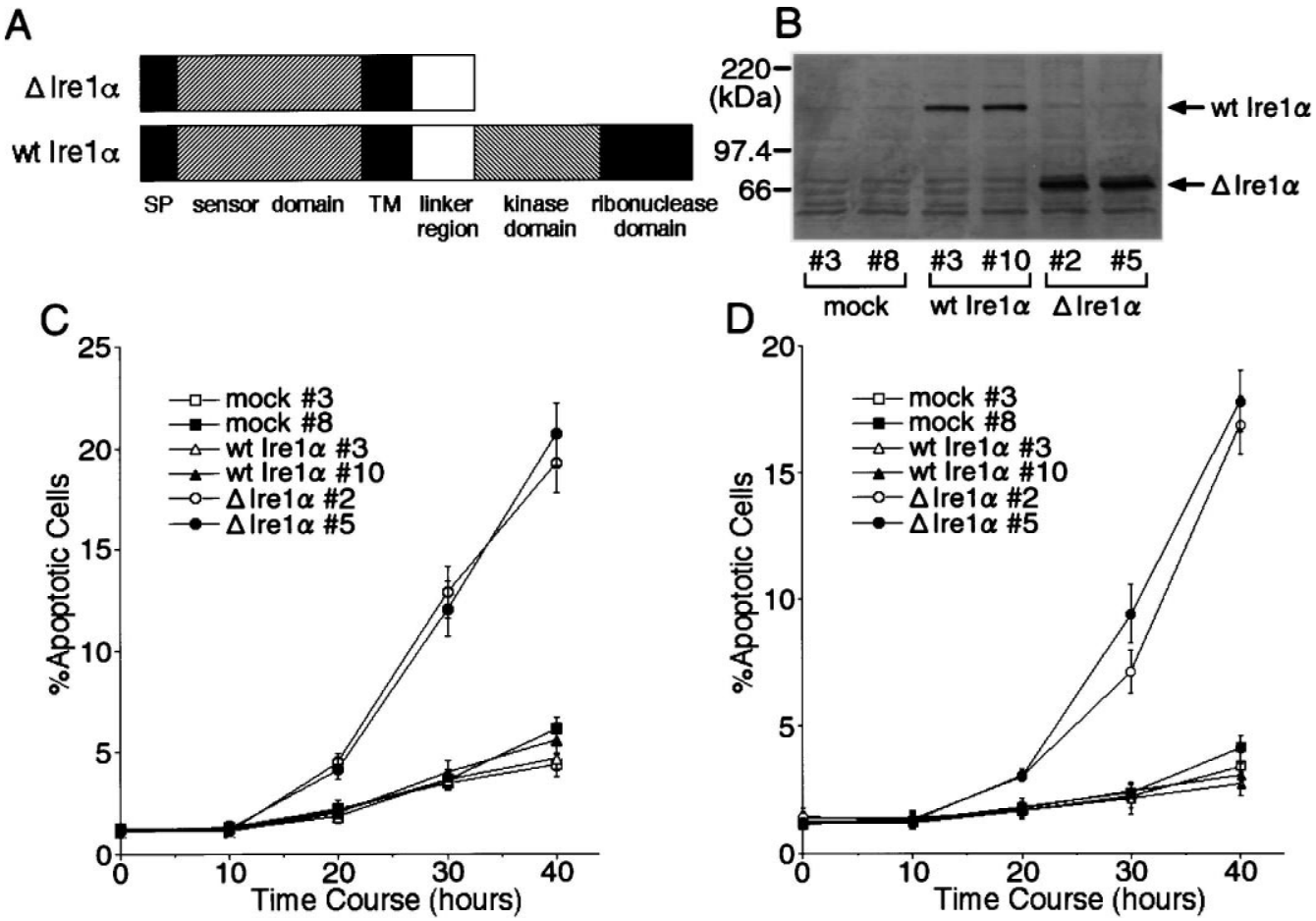

Fig. 4. The time-course of cell viability under conditions of ER stress was examined by investigating nuclear morphology. A truncated form of mouse Ire $1 \alpha, \Delta$ Ire $1 \alpha$, which lacks kinase and ribonuclease domains, was used for its dominant-negative effects on the UPR. The structures of $\Delta$ Ire $1 \alpha$ and wild-type Ire1 $\alpha$ are shown in (A). SP and TM refer to the potential signal peptide and the putative transmembrane domain, respectively. Neuro2a cells, a mouse neuroblastoma cell line, were stably transfected with mock (empty plasmid), wild-type Ire1 $\alpha$ or $\Delta$ Ire $1 \alpha$. Two lines were selected from the stable lines transfected with mock $(\# 3, \# 8)$, wild-type $(\# 3, \# 10)$ and $\Delta \operatorname{Ire} 1 \alpha(\# 2, \# 5)$, respectively. The expression levels of the transgenes in these lines were demonstrated by Western blot analysis (B). Arrows indicate wild-type Ire $1 \alpha$ and $\Delta$ Ire $1 \alpha$. Size markers (in kilodaltons) are on the left. At indicated time points after treatment with $2 \mu \mathrm{g} / \mathrm{ml}$ tunicamycin (C) or $3 \mu \mathrm{M}$ A23187 (D), the stable lines were stained with Hoechst 33258, and the average percentages of cells with chromatin condensation in randomly selected fields were scored as an indicator of apoptosis. Data are means \pm S.D. of four independent experiments.

\section{Discussion}

In the present study, we cloned the mouse homolog of Ire $1 \alpha$ for generating genetically modified mice. From the $92 \%$ identity of the amino acid sequence between mouse and human Ire $1 \alpha$, and the ubiquitous expression of Ire $1 \alpha$ mRNA in mouse tissues, it is likely that Ire $1 \alpha$ protein is a main stress sensor that plays an essential role in cell survival against ER stress in mammalian organs. Relatively high expression levels of Ire $1 \alpha$ were observed in thymus, liver and lung, suggesting the possibility that in these organs Ire1 $\alpha$ might participate in organ-specific stress response systems as well as the UPR. The low oxygen environment in embryonic circulation might be connected with the lower expression levels of Ire $1 \alpha$ mRNA in mouse brain at embryonic stages compared to postnatal and adult stages.

Like many types of nonneuronal cells, neurons respond to extracellular stimuli that provoke stressed conditions in the ER. For example, transient cerebral ischemia is known to induce a stress response which is in many respects identical to that triggered by the depletion of ER calcium pools, implying the possibility that disturbance of the ER calcium homeostasis may play a major role in ischemiainduced cell injury of neurons [9-11]. In the present study, in situ hybridization analysis has revealed that in mouse brain Ire $1 \alpha$ mRNA is preferentially expressed in cortical, hippocampal and olfactor neurons and in other neuronal cells containing Purkinje cells and brainstem neurons, suggesting that Ire $1 \alpha$ is the essential proximal sensor of the UPR pathway in neuronal cells.

We have previously reported that familial Alzheimer's disease (FAD) linked presenilin-1 mutations downregulate the signaling pathway of the UPR by affecting the phosphorylation of Ire1 $\alpha$ [4]. However, the character of the resulting vulnerability to ER stress has been unclear. Our present study, using a dominant-negative form of Ire $1 \alpha$, has revealed that the downregulation of the UPR enhances the apoptotic process under conditions of ER stress in a mouse neural cell line, by investigating the morphological changes of cells, activation of caspase- 3 and cytochrome $c$ release from mitochondria into the cytosol. Together with 
A
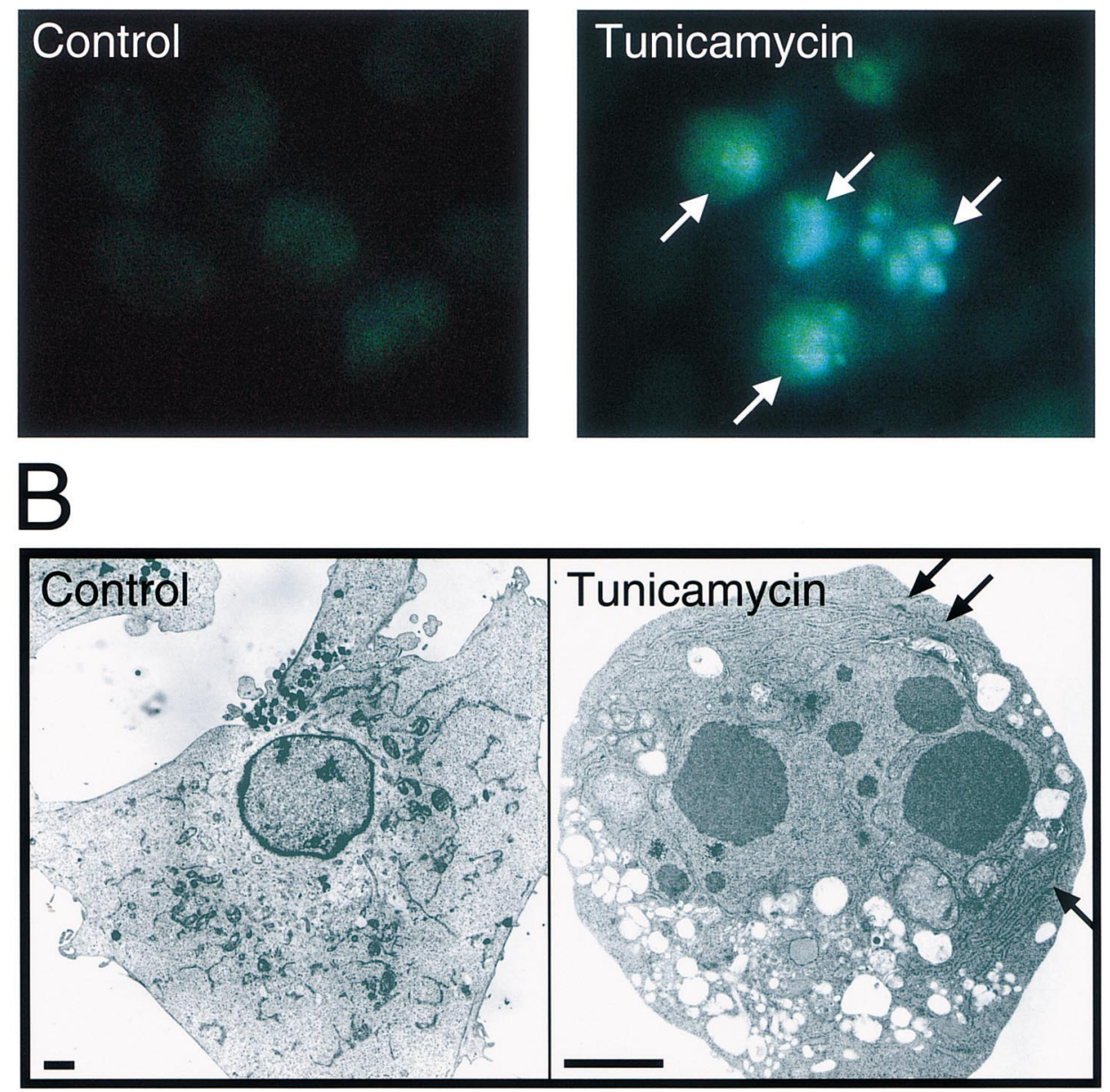

Fig. 5. Morphological study of Neuro2a cells expressing $\Delta$ Ire1 $\alpha$ treated with $2 \mu g / m l$ tunicamycin for 40 h. (A) Hoechst 33258 staining of tunicamycin-treated cells (right panel) and untreated Neuro2a cells (left panel). Arrows indicate the cells with chromatin condensation, which is the morphological feature of apoptosis. (B) Examination under electron microscopy of treated cells (right panel) and untreated cells (left panel). Enlarged ER lumens are indicated by arrows. Scale bars: $2 \mu \mathrm{m}$.

the preferential expression of Ire $1 \alpha$ in neuronal cells in mouse brain, this finding raises the possibility that the perturbed ER-stress response might be involved in the neuron-specific apoptosis observed in brains of Alzheimer's disease patients containing FAD ones. Enhanced apoptosis by the downregulation of the UPR in a mouse neural cell line suggests that transgenic mice with a dominant-negative form of Ire $1 \alpha$ targeted to neurons would be a good animal model for evaluating the effects of the disturbed stress response on the mammalian nervous system, and that generating genetically modified mice on Ire $1 \alpha$ including dominant-negative form transgenic mice might contribute to further understanding of the pathogenic mechanisms of Alzheimer's disease and other neurodegenerative disorders.

In our analysis by in situ hybridization for Ire $1 \alpha$ mRNA,

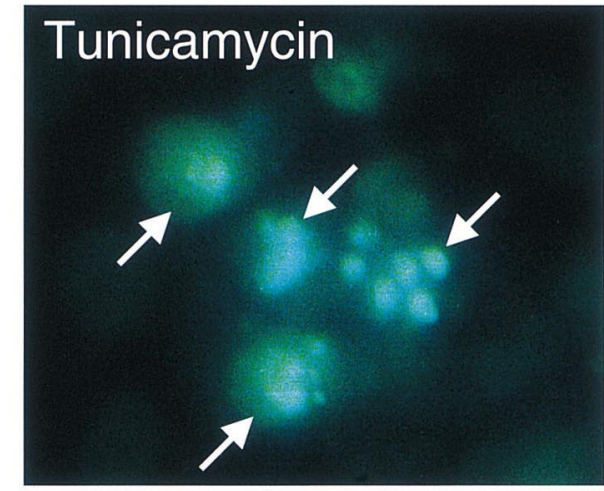



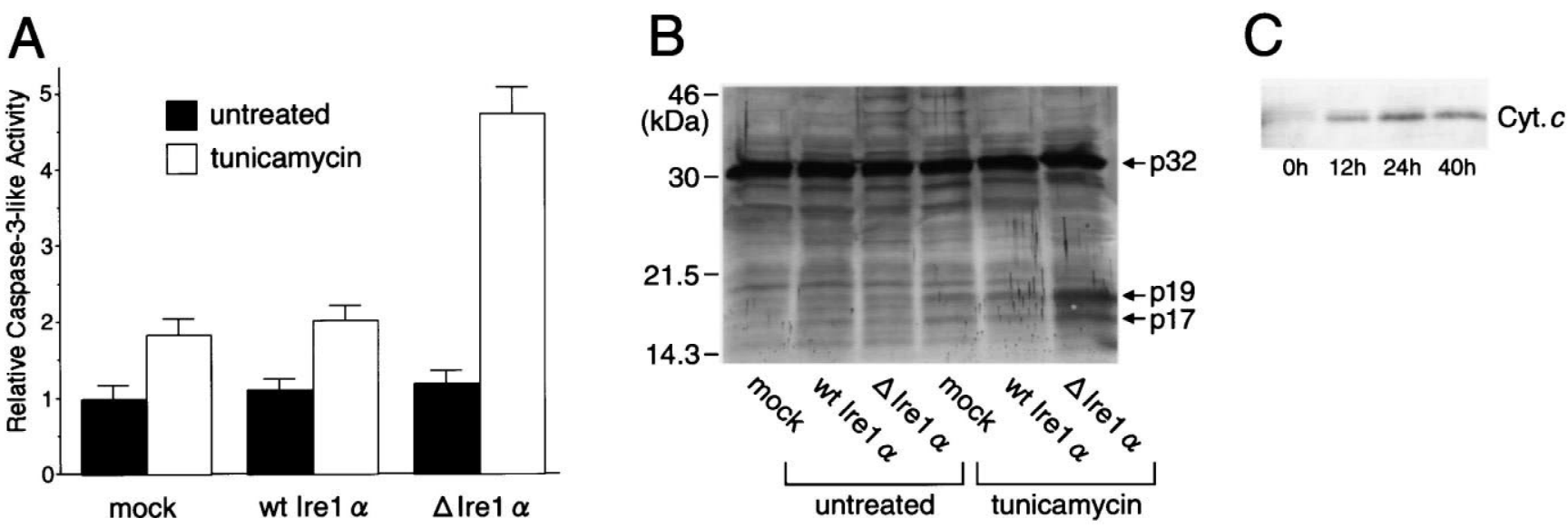

Oh $12 \mathrm{~h} 24 \mathrm{~h} 40 \mathrm{~h}$

Fig. 6. The activation of caspase-3 and the release of cytochrome $c$ from mitochondria into the cytosol were analyzed as indicators of apoptosis to investigate the effects of the downregulation of the UPR. (A) Caspase-3-like protease activity in ER-stress exposed Neuro2a lines stably transfected with mock (\#3), wild-type Ire1 $\alpha$ (\#3) or $\Delta \operatorname{Ire} 1 \alpha(\# 2)$. At $40 \mathrm{~h}$ after treatment with $2 \mu \mathrm{g} / \mathrm{ml}$ tunicamycin, Ac-DEVD-MCA cleaving activity in the cell extracts was measured. Values represent caspase-3-like activities relative to untreated Neuro2a cells expressing mock, and are shown as means \pm S.D. of three independent experiments. (B) The cleavage of caspase-3 in ER-stress exposed Neuro2a cells expressing mock, wild-type Ire1 $\alpha$ or $\Delta$ Ire1 $\alpha$. Following treatment with $2 \mu \mathrm{g} / \mathrm{ml}$ tunicamycin for $40 \mathrm{~h}$, the cell lysates which contained equal amounts of protein $(30 \mu \mathrm{g})$ were subjected to Western blot analysis using an anti-caspase- 3 antibody that can detect both pro-caspase-3 and active subunits. Arrows indicate pro-caspase-3 (p32) and active subunits (p19, p17). Size markers (in kilodaltons) are on the left. (C) The release of cytochrome $c$ from mitochondria into the cytosol in ER-stress exposed cells. At indicated time points after treatment with $2 \mu \mathrm{g} / \mathrm{ml}$ tunicamycin, Neuro2a cells expressing $\Delta$ Ire1 $\alpha$ were harvested, homogenized and separated as cytosol and membrane fractions by ultracentrifugation. Equal amounts of protein $(6 \mu \mathrm{g})$ from the cytosol fraction were subjected to Western blot analysis using an anti-cytochrome $c$ antibody.

investigate the mechanisms by which the accumulation of unfolded proteins in the ER provokes downstream apoptotic signaling in neuronal cells.

\section{References}

[1] J.S. Cox, C.E. Shamu, P. Walter, Transcriptional induction of genes encoding endoplasmic reticulum resident proteins requires a transmembrane protein kinase, Cell 73 (1993) 1197-1206.

[2] T. Fernandes-Alnemri, R.C. Armstrong, J. Krebs, S.M. Srinivasula, L. Wang, F. Bullrich, L.C. Fritz, J.A. Trapani, K.J. Tomaselli, G. Litwack, E.S. Alnemri, In vitro activation of CPP32 and Mch3 by Mch4, a novel human apoptotic cysteine protease containing two FADD-like domains, Proc. Natl. Acad. Sci. USA 93 (1996) 7464 7469.

[3] K. Imaizumi, M. Tsuda, A. Wanaka, M. Tohyama, T. Takagi, Differential expression of sgk mRNA, a member of the Ser/Thr protein kinase gene family, in rat brain after CNS injury, Mol. Brain Res. 26 (1994) 189-196.

[4] T. Katayama, K. Imaizumi, N. Sato, K. Miyoshi, T. Kudo, J. Hitomi, T. Morihara, T. Yoneda, F. Gomi, Y. Mori, Y. Nakano, J. Takeda, T. Tsuda, Y. Itoyama, O. Murayama, A. Takashima, P. St George-Hyslop, M. Takeda, M. Tohyama, Presenilin-1 mutations downregulate the signalling pathway of the unfolded-protein response, Nat. Cell Biol. 1 (1999) 479-485.

[5] R.M. Kluck, E. Bossy-Wetzel, D.R. Green, D.D. Newmeyer, The release of cytochrome $c$ from mitochondria: a primary site for Bcl-2 regulation of apoptosis, Science 275 (1997) 1132-1136.

[6] R.M. Kluck, S.J. Martin, B.M. Hoffman, J.S. Zhou, D.R. Green, D.D. Newmeyer, Cytochrome $c$ activation of CPP32-like proteolysis plays a critical role in a Xenopus cell-free apoptosis system, EMBO J. 16 (1997) 4639-4649.

[7] X. Liu, C.N. Kim, J. Yang, R. Jemmerson, X. Wang, Induction of apoptotic program in cell-free extracts: requirement for dATP and cytochrome $c$, Cell 86 (1996) 147-157.
[8] K. Mori, W. Ma, M.J. Gething, J. Sambrook, A transmembrane protein with a cdc2 $+/ \mathrm{CDC} 28$-related kinase activity is required for signaling from the ER to the nucleus, Cell 74 (1993) 743-756.

[9] W. Paschen, Disturbances of calcium homeostasis within the endoplasmic reticulum may contribute to the development of ischemiccell damage, Med. Hypotheses 47 (1996) 283-288.

[10] W. Paschen, J. Doutheil, C. Gissel, M. Treiman, Depletion of neuronal endoplasmic reticulum calcium stores by thapsigargin: effect on protein synthesis, J. Neurochem. 67 (1996) 1735-1743.

[11] W. Paschen, J. Doutheil, Disturbance of endoplasmic reticulum functions: a key mechanism underlying cell damage?, Acta. Neurochir. Suppl. 73 (1999) 1-5.

[12] C.E. Shamu, P. Walter, Oligomerization and phosphorylation of the Ire1p kinase during intracellular signaling from the endoplasmic reticulum to the nucleus, EMBO J. 15 (1996) 3028-3039.

[13] C. Sidrauski, P. Walter, The transmembrane kinase Ire1p is a site-specific endonuclease that initiates mRNA splicing in the unfolded protein response, Cell 90 (1997) 1031-1039.

[14] C. Sidrauski, R. Chapman, P. Walter, The unfolded protein response: an intracellular signalling pathway with many surprising features, Trends Cell Biol. 8 (1998) 245-249.

[15] N.A. Thornberry, Y. Lazebnik, Caspases: enemies within, Science 281 (1998) 1312-1316.

[16] W. Tirasophon, A.A. Welihinda, R.J. Kaufman, A stress response pathway from the endoplasmic reticulum to the nucleus requires a novel bifunctional protein kinase/endoribonuclease (Ire1p) in mammalian cells, Genes Dev. 12 (1998) 1812-1824.

[17] X.Z. Wang, H.P. Harding, Y. Zhang, E.M. Jolicoeur, M. Kuroda, D. Ron, Cloning of mammalian Ire1 reveals diversity in the ER stress responses, EMBO J. 17 (1998) 5708-5717.

[18] A.A. Welihinda, R.J. Kaufman, The unfolded protein response pathway in Saccharomyces cerevisiae. Oligomerization and transautophosphorylation of $\operatorname{Ire} 1 \mathrm{p}(\mathrm{Ern} 1 \mathrm{p})$ are required for kinase activation, J. Biol. Chem. 271 (1996) 18181-18187.

[19] J. Yang, X. Liu, K. Bhalla, C.N. Kim, A.M. Ibrado, J. Cai, T.I. Peng, D.P. Jones, X. Wang, Prevention of apoptosis by Bcl-2: release of cytochrome $c$ from mitochondria blocked, Science 275 (1997) $1129-1132$. 